\title{
Reverse Reduction Ratio Effect on the Bonding Strength of 7075 Al/AZ31B Mg/7075 Al Laminated Composite Fabricated by Hot Rolling

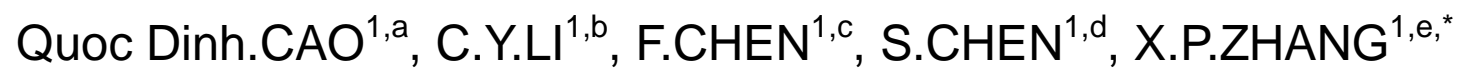 \\ ${ }^{1}$ Department of Materials Science and Engineering, Nanjing University of Science and Technology, Nanjing 210094, China \\ agaoguoding90@gmail.com, b1067911365@qq.com, 'chenf1990@163.com, d592001575@qq.com, e, ${ }^{*}$ xpzhang@njust.edu.cn \\ ${ }^{*}$ Corresponding author
}

Keywords: Hot Rolling, Reduction Ratio, Bonding Strength, Aluminum Alloy, Magnesium Alloy, Finite Element Methods (FEM).

Abstract. Reduction ratio is one of the most important parameters that affect final bonding strength of laminated composites fabricated by hot rolling. In general, the bonding strength increases with the reduction ratio. However, it was found that the reduction ratio had a reverse effect on the bonding strength of the $7075 \mathrm{Al} / \mathrm{AZ31B} \mathrm{Mg} / 7075 \mathrm{Al}$ laminated composites prepared by hot rolling. Microstructure, elements distribution, and phase constitution in the bonded interface of the laminated composites at different reduction ratios were investigated, and the hot rolling process was simulated by finite element methods (FEM). The results show that a larger reduction ratio would lead to: a wider of diffusion layer with a relatively lower strength; a larger secondary tensile stress; and a larger relative slipping distance after the formation of the bonded interface. All of them induced the reverse effect.

\section{Introduction}

Cold or hot roll bonding is a solid phase welding method, by which same or different metals are bonded together through rolling-deformation at room or elevated temperature. Both of cold and hot roll methods have been applied to fabricating laminated composites [1-5]. There are many factors would affect the final bonding strength and the formation of interfacial-bonding area [3-5]. Besides bonding temperature [3] and annealing treatment [4], reduction ratio is one of the most important parameters. It is commonly reported that bonding strength of a laminated composite increases with the reduction ratio [1, 4-5], due to the increase contact mean pressure and the overlapping surface exposure at the interface. However, here we report a reverse case: bonding strength of 7075Al/AZ31B Mg/7075 Al laminated composite decreased with increasing reduction ratio. The laminated composite was prepared by hot rolling at different reduction ratios. To explain the abnormal effect, microstructure, elements distribution and phase constitution of the bonded interface of the laminated composites at different reduction ratios were investigated, and the hot rolling process was simulated by FEM.

\section{Experimental Procedures}

\section{Material and Processing}

As-annealed AZ31B magnesium alloy and 7075 aluminum alloy ingots were cut into rectangular pieces with a dimension of $100 \mathrm{~mm} \times 75 \mathrm{~mm} \times 10 \mathrm{~mm}$ and $100 \mathrm{~mm} \times 75 \mathrm{~mm} \times 5 \mathrm{~mm}$, respectively. All of the plates were polished up to 600\# $\mathrm{SiC}$ paper in order to remove oxidation films and bring forth a rough surface. An assembly was made of three plates, one $\mathrm{Mg}$ alloy placed in the middle with $\mathrm{Al}$ plates placed on the both outsides. The assembly was welded along one side to avoid the plates' separation before their entrance into the roll gap. Hot rolling was carried out with three reduction ratios, viz. $60 \%, 70 \%$ and $80 \%$ (single pass). The diameter of the roller was $500 \mathrm{~mm}$, and the rotational speed was $60 \mathrm{rpm}$. 


\section{Bonding Strength Test}

Dog-bone flat specimens along the rolling direction were prepared for the bonding strength tests. More details on the bonding strength test could be found in Ref. [2].

\section{Characterization}

Microstructure and chemical component of the bond interface were characterized by scanning electron microscopy (SEM) and energy-dispersive X-ray spectroscopy (EDX). X-ray diffraction (XRD) with $\mathrm{Cu} \mathrm{K \alpha}$ radiation was used to determine the phase composition of the testing specimens.

\section{Results and Discussion}

\section{Microstructure and Composition Characterization}

After hot rolling, equiaxed grains were clearly observed in the interfacial microstructure of the composite. This indicates dynamic recrystallization took place during the hot rolling. Grains size increased with the distance away from the interface. In order to determine the element distribution across the bonding interface, elemental line scan of $\mathrm{Al}$ and $\mathrm{Mg}$ using EDX was performed. There was an absence of intermetallics in the bonding structure. A diffusion layer existed in the interface. In the diffusion layer, the concentration of the element $\mathrm{Al}$ decreased from the $7075 \mathrm{Al}$ alloy to the AZ31B Mg alloy, and the concentration of element Mg was the opposite case.

The width of the diffusion layer ranged from $4 \mu \mathrm{m}$ to $6 \mu \mathrm{m}$. The width of the diffusion layer increased with the reduction ratio. The severe plastic deformation during hot rolling would induce a temperature rise, which increased with the reduction ratio. The diffusion coefficient in solids increases with temperature, thus the width of the diffusion layer increased with the reduction ratio.

The composition of the interface was further analyzed by XRD. The results showed that the fractured surface of the $\mathrm{Al}$ plate was mainly consisted of $\alpha$-Al and small amount of $\mathrm{Al}_{3} \mathrm{Mg}_{2}$, while that of the $\mathrm{Mg}$ plate was mainly consisted of $\beta-\mathrm{Mg}$ and $\mathrm{Al}_{3} \mathrm{Mg}_{2}$.

\section{Bonding Strength of the Experimental Laminated Composite}

Fig. 1 shows the representative bonding strength curves of the Al-Mg laminated composite. With increasing tensile strain, the stress increased to a stable state, and then decreased to a second stable state. The shear stress needed to separate the bonded interface of the sample hot rolled under $450{ }^{\circ} \mathrm{C}$ and with a reduction ratio of $60 \%$ was about $55 \mathrm{MPa}$. It is also noted that the ductility decreased with the reduction ratio.

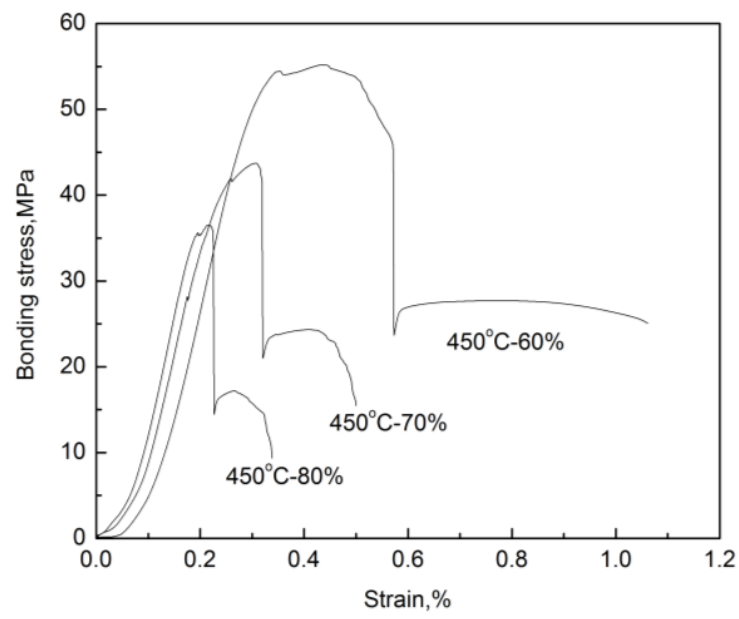

Fig. 1 Representative bond strength curves of the experimental laminated composite obtained at room temperature

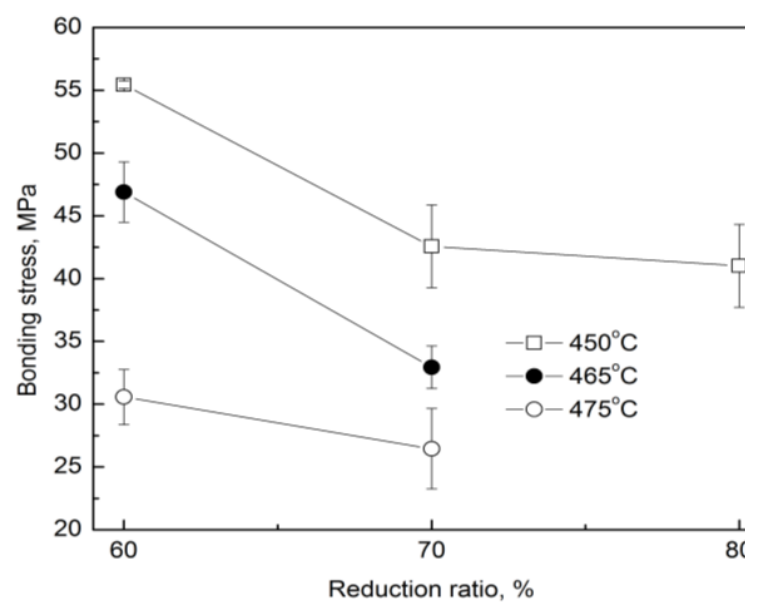

Fig. 2 Effects of reduction ratio on bonding strength of the experimental laminated composites fabricated by hot rolling 


\section{Effects of Reduction Ratio on the Bonding Strength}

In general, increasing reduction ratio would cause increasing bonding strength, due to the enhanced pressure, increasing surface area, number of cracks and weld area proportion [1]. In the present study, however, the case was just the opposite: bonding strength increased with the decreasing reduction ratio, as shown in Fig. 2. For the sample rolled at $450{ }^{\circ} \mathrm{C}$, the bonding strength peaked at $55 \mathrm{MPa}$ with a reduction ratio of $60 \%$, whilst it decreased to 41 and $37 \mathrm{MPa}$ with reduction ratios of 70 and $80 \%$, respectively. For the sample rolled at $465{ }^{\circ} \mathrm{C}$, the bonding strength decreased from $47 \mathrm{MPa}$ to $33 \mathrm{MPa}$ when the reduction ratio increased from $60 \%$ to $70 \%$.

There was no observable change in the interfacial microstructures, phases and elemental distribution, as discussed above. The only distinctive for all cases was the difference of diffusion layer width. From the experiment results, the laminated composites were separated along the interface during the bonding test, which indicated the shear strength of the diffusion layer was lower than that of the Al Moreover, the difference of plastic deformation of the plates and relative slipping of the interface at different reduction ratios also influenced the bonding strength. It was difficult to measure the plastic deformation and the relative slipping distance during the hot rolling. Hence, the rolling process was simulated by finite element methods using Deform 2D software. More details on the FEM simulation could be found in Ref. [6]. The plastic deformation stress-strain curves of the experimental alloys at different temperature and strain rate were measured by the Gleeble- 1500 . The geometric model is shown in Fig. 3. All nodes were chosen at the section of $X=20 \mathrm{~mm}$ along the rolling direction (see Fig. 3). Node P1 and P2 were chosen at the top and the bottom surface of the Al plate. Node $\mathrm{P} 3$ was selected at the top surface of the $\mathrm{Mg}$ plate. To a certain extent, increasing the diffusion layer width contributed to a decreasing the bonding strength.

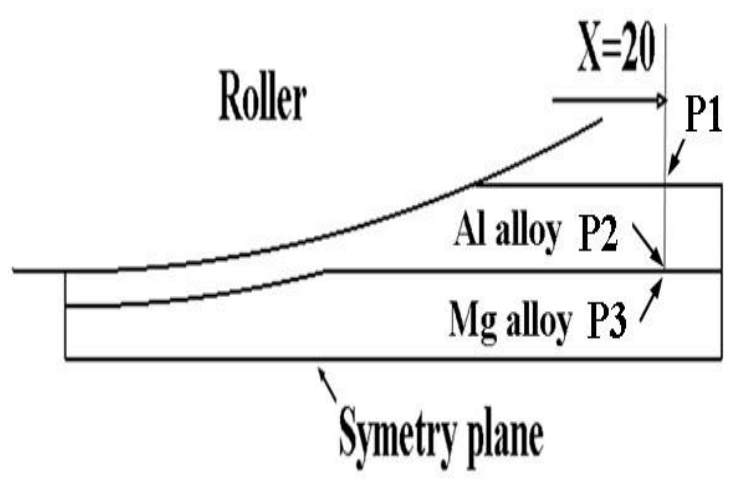

Fig. 3 Subsection geometric model and the typical position nodes

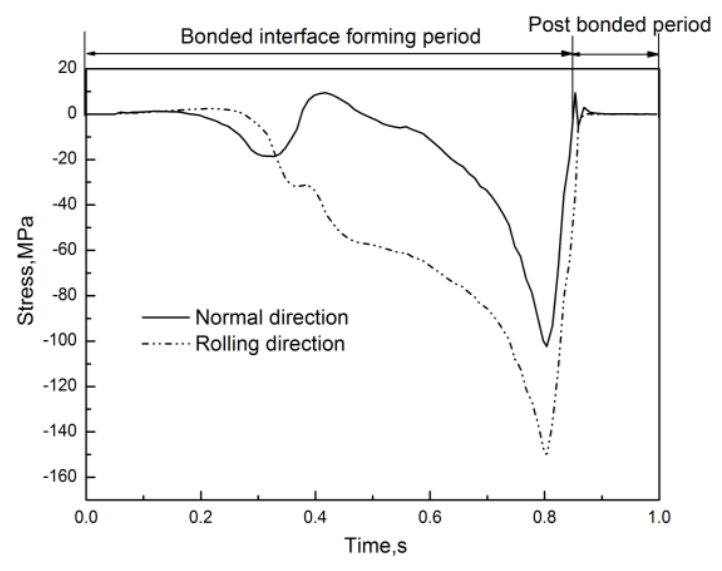

Fig. 4 Stress history of the node P1 during the hot rolling

The stress history of the node P3 during the rolling is shown in Fig. 4. It was found that both of the compression stress and tensile stress appeared during the hot rolling. When the time was about $0.8 \mathrm{~s}$, meanwhile, the node P3 was passing the narrowest section of the roll gap; the stress was a compression stress and reached the maximum value. After that, the stress sharply changed to a tensile stress. Second tensile stress is one of the key factors for a fracture [7], which would cause damage to the bonded interface and reduce the final bonding strength. Thus, there were two stages existing during the hot rolling. The first one was the bonded interface forming period, which started from the beginning of the rolling to the stress reached the maximum compression stress and then decreased to zero. During this period, the interface bonding formed due to the extrusion of virgin metals. The second one was the post-bonded period. It began from the end of the first period to the end of the rolling. During this period, the bonded interface was subjected to a secondary tensile stress, which would damage the bonded interface. For an ultimate case, the bonded interface would be torn out, resulting in the plates' separation. 


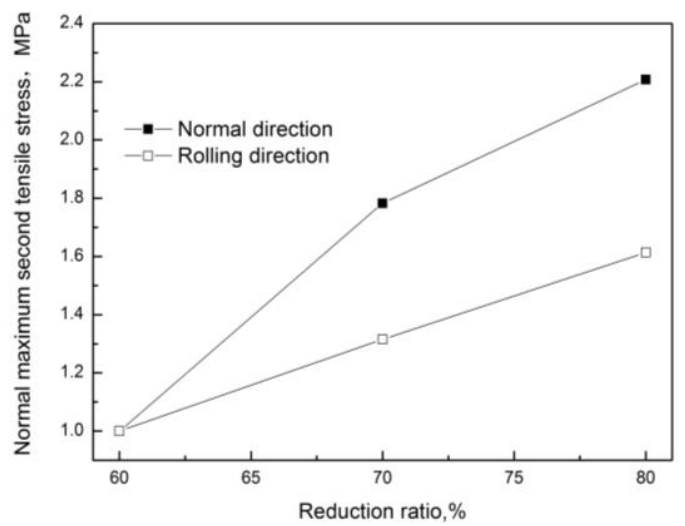

Fig. 5 Maximum values of the second tensile stress at different reduction ratios

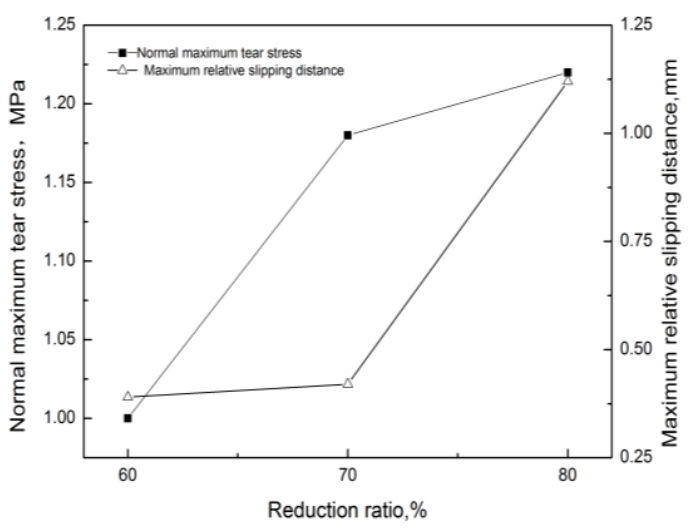

Fig. 6 Normal maximum tear stress of node P1 and normal maximum relative slipping distance at different reduction ratios after the formation of the bonded interface

The maximum second tensile stress increased with the reduction ratio, as shown in Fig. 5. A relatively larger reduction ratio led to a relatively larger secondary tensile stress, and hence a relatively lower final bonding strength. In addition, it is necessary to note that the Al plates may stick to the roller surface because of the sticking friction during the rolling [8], and it tends to tear the interface of the plates and reduce the final bonding strength. The maximum tear stress of the node $\mathrm{P} 1$ caused by the adhesion of the $\mathrm{Al}$ plates to the roller at different reduction ratio is shown in Fig. 6. The maximum tear stress increased with the reduction ratio, too. Similarly, a relatively larger reduction ratio led to a relatively larger tear stress and hence lowers the final bonding strength.

It was found that a relative slipping existed on the interface between the $\mathrm{Al}$ and $\mathrm{Mg}$ plate during hot rolling. It was in good agreement with Zhao et al. [8], who reported a relative slipping exists on the interface between $\mathrm{Ti}$ alloy plate and stainless steel plate during hot rolling. Before the Al plate bonded with the Mg plate, the relative slipping was a positive factor for the bonded due to it breaks the oxide film to reveal the fresh surfaces and promotes the contacting between the interfaces to be bonded. On the other hand, the relative slipping was a negative factor for the bonded interface. It may break the bonding of these plates. The maximum relative slipping between the node P2 and the node P3 at different reduction ratios after the bonding strength formed are shown in Fig. 6. A relatively larger reduction ratio led to a relatively larger relative slipping distance after the bonding strength formed and hence a relatively lower final bonding strength.

\section{Summary}

A reverse phenomenon, decreasing reduction ratio leading to increasing bonding strength of an $\mathrm{Al} / \mathrm{Mg}$ laminated composites, was studied. It was found that:

(i) There was no observable change in the interfacial microstructures, phases and elemental distribution in the samples with different reduction ratios.

(ii) Two stages existed during hot rolling, viz. bonded interface-forming period and post-bonded period. During the latter, the bonded interface was subjected to damage due to a secondary tensile stress.

(iii) The width of the diffusion layer, the second tensile stress, the tear stress, and the relative slipping contributed to the reverse effect of the reduction ratio on the bonding strength.

\section{Acknowledgement}

This work was supported by Jiangsu Qinglan Project; the Scientific Research Foundation for the Returned Overseas Chinese Scholars, State Education Ministry; the Fundamental Research Funds 
for the Central Universities, No. 30920140112008; Key Graduation Project of Nanjing University of Science and Technology.

\section{References}

[1] M. Abbasi, M.R. Toroghinejad: Effects of Processing Parameters on the Bond Strength of Cu/Cu Roll-bonded Strips, J. Mater. Process. Technol. , 2010, 210, 560-563.

[2] X.P. Zhang, T.H. Yang, J.Q. Liu, et al : Mechanical Properties of an Al/Mg/Al Trilaminated Composite Fabricated by Hot Rolling, J. Mater. Sci. , 2010, 45, 3457-3464.

[3] X.P. Zhang, T.H. Yang, S. Castagne, et al : Microstructure, Bonding Strength and Thickness Ratio of Al/Mg/Al Alloy Laminated Composites Prepared by Hot Rolling, Mater. Sci. Eng. A, 2011, 528, 1954-196.

[4] X.P. Zhang, T.H. Yang, S. Castagne, et al : Entrance Analysis of 7075 Al/Mg-Gd-Y-Zr/7075 Al Laminated Composite Prepared by Hot Rolling and Its Mechanical Properties, Mater. Des., 2011, 32, 1152-1158.

[5] M. Movahedi, H.R. Madaah-Hosseini, A.H. Kokabi: The Influence of Roll Bonding Parameters on the Bond Strength of Al-3003/Zn Soldering Sheets, Mater. Sci. Eng. A, 2008, 487, 417-423.

[6] X.P Zhang, M.J. Tan, T.H. Yang, et al: Isothermal Rolling of Mg-based Laminated Composites Made by Explosion Cladding, Key Eng. Mater. , 2010, 43, 614-619.

[7] J.A. Schey: Fracture in Rolling Processes, J. Applied Metalworking,1980, 1,48-59.

[8] D.S. Zhao, J.C. Yan, Y. Wang, et al: Relative Slipping of Interface of Titanium Alloy to Stainless Steel During Vacuum Hot Roll Bonding, Mater. Sci. Eng. A ,2009, 499, 282-286. 